\title{
Bonecos e audiovisual, uma proposição pedagógica
}

Puppets and audiovisual, a pedagogical proposition

Paulo Balardim ${ }^{1}$ 


\section{Resumo}

Este artigo registra o conteúdo ministrado em atelier durante o Pro-Vocation - 2․ Rencontre Internationale sur la Formation aux Arts de la Marionnette, de 20 a 24 de junho de 2017, no Théâtre Municipal Tony Bulandra, em Targoviste, Romênia, em colaboração com a UNIMA - Union Internationale de la Marionnette. $O$ atelier realizou e discutiu exercícios práticos, fazendo uso de uma aproximação pedagógica entre o Teatro de Bonecos e o audiovisual, abordada como recurso didático para o ator-animador.

Palavras-chave: Bonecos; audiovisual; ator-animador; formação

\section{Abstract}

This article records the content taught in a practical workshop during Pro-Vocation - 2nd. Rencontre Internationale sur la Formation aux Arts de la Marionnette, from 20 to 24 June 2017, at the Théâtre Municipal Tony Bulandra in Targoviste, Romania, in collaboration with UNIMA - Union Internationale de la Marionnette. The workshop tried to discuss practical exercises, using a pedagogical approach between the Puppet Theater and the audiovisual, approached as didactic resource for the puppeteer.

Keywords: Puppets; audiovisual; puppeteer; puppetry training

ISSN: 1414.5731

E-ISSN: 2358.6958

1 Prof. Dr. Adjunto atuando na graduação e na pós-graduação em teatro (PPGT), do Centro de Artes (CEART), da Universidade do Estado de Santa Catarina (UDESC). paulobalardim@gmail.com 
Temos percebido que a tecnologia pode colaborar com o desenvolvimento de algumas de nossas habilidades ${ }^{2}$, ou, como salienta Chantal Hébert e Irène Perelli-Contos, as novas tecnologias as quais vivenciamos têm sido responsáveis pela "alteração de hábitos de percepção" (In: Picon-Vallin, 1998, p.173). Podemos conhecer novos lugares (outras épocas ou até mesmo outros planetas) sem sair de casa, podemos contatar emoções por meio de videojogos, podemos compartilhar nossas experiências por meio do computador, do tablet e do telefone. Podemos vivenciar o fantástico, o irreal e o sonho ao operar uma interface de utilizador que nos forneça os meios de interação entre homem e máquina e, desta forma, ter acesso a este universo virtual que a evolução digital nos permitiu. A tecnologia está entrelaçada com nossa cultura, com nossos hábitos, no modo de nos reconhecermos e de nos projetarmos e na maneira como deciframos e entendemos 0 mundo. $O$ relacionamento entre humanos é cada vez mais mediado por máquinas, por sistemas digitais. E podemos constatar que isso afeta profundamente nossa constituição psicofísico-social, pois nossas ações, comportamentos e práticas são "atravessados" pela tecnologia digital 3 . Mas o que nos interessa aqui é pensar de que forma podemos introduzir algumas práticas que utilizem a tecnologia de forma colaborativa no processo de ensino-aprendizagem com o Teatro de Bonecos ${ }^{4}$. O que ela pode nos oferecer?

Se, há algumas décadas atrás, habitar um boneco era uma experiência restrita ao ator-animador, hodiernamente é corriqueiro o uso de um "avatar" como projeção de nosso self. Vivenciar a experiência de estar num outro corpo, num outro tempo e num espaço diferente, já não é algo estranho ou distante. Dessa forma, com a intensificação da experiência por meio de equipamentos móveis que nos fornecem o "dom da ubiquidade" , temos nos capacitado cada vez mais à projeção consciente de nossa "auto-imagem ficcionada" para dentro desses suportes interativos. No entanto, apesar de estarmos imersos nessa avalanche de $\mathrm{NTCls}^{6}$, como assimilarmos a tecnologia para aprimorar processos pedagógicos ou, como podemos incorporar novas práticas, mesmo que para fornecer diferentes estímulos ao estudo de técnicas já consolidadas?

Provocado por esta questão, ministrei o atelier $O$ vídeo como estimulante e suporte pedagógico (La vidéo comme stimulant et soutien pédagogique) durante o Pro-Vocation - 2‥ Rencontre Internationale sur la Formation aux Arts de la Marionnette, encontro realizado de 20 a 24 de junho de 2017, no Théâtre Municipal Tony Bulandra, em Targoviste, Romênia, em colaboração com a Comissão de Formação Profissional da UNIMA - Union Internationale de la Marionnette. O atelier ocorreu no dia 21 de junho, das $10 \mathrm{~h} 30 \mathrm{~min}$ às $12 \mathrm{~h}$, e teve como objetivo principal pensar o uso do vídeo

\footnotetext{
${ }^{2}$ A respeito da interação entre espaços físicos e virtuais, Lúcia Santaella (PUC/SP) discorre sobre os dispositivos tecnológicos como prolongamentos da capacidade humana para produzir linguagem, frutos de um desenvolvimento (multiplicação e diversificação) do conhecimento. Entrevista para o programa Canal Sempre Um Papo, publicado em 26 de março de 2009. Disponível em https://www.youtube.com/watch?v=XhRgfLuZXNY. Acesso em 01/04/2018.

${ }^{3}$ Podemos constatar em inúmeros filmes e séries a crescente aproximação temática com o assunto. Como exemplo, temos a série Black Mirror (2011-2017), que trata da perniciosidade do uso indiscriminado da tecnologia. Nos episódios da série despontam questionamentos éticos e filosóficos sobre os limites interativos entre homem e máquina e sobre a mediação dos relacionamentos humanos por meio de interfaces digitais. Também é o caso das séries WestWorld (2016), Altered Carbon (2018), entre outros exemplos de séries que poderíamos citar e, à exemplo de filmes, temos a premiada trilogia Matrix (The Matrix-1999/Matrix Reloaded e Matrix Revolutions-2003), Total Recall (2012), Oblivion (2013), The Cloverfield Paradox (2018) e, recentemente, Anon (2018).

4 O Teatro de Bonecos é um vasto campo que oferece muitas possibilidades para investigações poéticas, e associado ao audiovisual, pode gerar um produto artístico híbrido. Sua prática como meio de expressão de ideias e conceitos pode realizar uma concretização ficcional que auxilie na reinterpretação do mundo a partir da subversão de uma realidade dada, onde a ressignificação torna possível uma ampliação semiológica do sentido do real.

5 Termo utilizado por Lúcia Santaella (referência supracitada)

${ }^{6}$ Novas Tecnologias de Comunicação e Informação.
} 
como um processo pedagógico para a formação do ator-animador, reconhecendo algumas especificidades da técnica de animação, principalmente relacionadas ao tipo de boneco utilizado para o atelier e ao potencial expressivo dele no vídeo 7 .

Este atelier foi um dos seis ateliers práticos ministrados durante o encontro em Targoviste. A proposta dos ateliers realizados pelas manhãs era a de apresentar perspectivas pedagógicas a partir de exercícios práticos que pudessem expor metodologias pessoais utilizadas para o ensino do Teatro de Animação ${ }^{8}$. O objetivo dos ateliers práticos foi justamente fornecer conteúdo para as discussões teóricas que ocorreram durante as tardes, as quais abordavam as transformações ocorridas no Teatro de Animação, entre elas a hibridação proveniente do contato com outras artes nas últimas décadas, e as atuais estratégias para o ensino desta arte multifacetada frente a essas mudanças.

Desta forma, o conteúdo que ministrei no atelier e que apresento aqui, no que concerne à técnica de animação, apenas recapitula alguns conceitos e procedimentos basilares que vem sendo utilizados na formação do ator-animador ${ }^{9}$. No entanto, destaco que, ao introduzir o recurso do vídeo como suporte para gerar um feedback em tempo real para o ator, a câmera e o monitor se apresentam como ferramental de autodisciplina e reflexão crítica sobre si mesmo, a partir do desenvolvimento de uma observação criteriosa, que poderá ser mediada por um agente externo (um colega ou um professor).

Assim, ao propor índices de um método de abordagem do ensino-aprendizagem de elementos práticos da animação, cabe ressalvar que, embora o manuseio operacional dos bonecos apresente problemáticas simples de manipulação do ponto de vista mecânico, isso manifesta apenas a superfície do método. Uma análise mais aprofundada perceberá que estamos induzindo caminhos de estímulos para uma nova construção imagética sobre si mesmo, sobre o mundo, e encontrando outros modos de acionar no corpo do ator uma via de expressão pessoal e de representação. Se, na formação do ator-animador, a propriocepção é etapa importante para a compreensão do movimento transmitido ao corpo do boneco, o que defendemos como hipótese neste trabalho é que a construção desta imagem mental do ator sobre o esquema corporal do boneco (e também sobre seu próprio corpo), quando mediada pela observação "distanciada" propiciada pela imagem produzida no monitor, põe em questão um duplo desdobramento do ator, o qual se projeta não apenas no boneco que manipula, mas também na imagem virtualizada desse boneco. Quer dizer, temos, então, do ponto de vista perceptivo, uma complexidade, pois não basta apenas "ver" e "sentir" o corpo do boneco tridimensional por meio do contato físico com o ator, para então nele projetar ações inteligíveis. É necessário, além disso, estar atento à realidade ficcional criada dentro do enquadramento explícito no vídeo, a qual se difere em muitos aspectos da realidade do espaço do corpo físico do boneco. Podemos

\footnotetext{
${ }^{7}$ Participaram do atelier cinco estudantes de teatro da Romênia e alguns artistas e pesquisadores presentes no encontro. 0 atelier ocorreu no palco do Théâtre Municipal Tony Bulandra. Os demais participantes do encontro assistiram ao atelier sentados na plateia, manifestando-se no debate final sobre a metodologia aplicada.

${ }^{8} \mathrm{O}$ estudo do cruzamento do Teatro de Animação com o audiovisual também fez parte de meu projeto de pesquisa realizado na UDESC no ano de 2017, bem como foi tema da disciplina que ministrei no PPGT-UDESC no mesmo ano.

${ }_{9}^{9}$ Podemos verificar que muitos dos exercícios aplicados estão presentes em livros dedicados à arte da animação de bonecos, como é o caso da obra de Carlos Converso (2000), René Santana (1989), Paco Parício e Pilar Amorós (2000), Andre-Charles Gervais (1947). Nessa última obra, intitulada Marionnettes et marionnettistes de France, verificamos um importante capítulo que registra uma coletânea de exercícios práticos para o desenvolvimento mecânico de habilidades de manipulação.
} 
dizer que uma dessas diferenças se encontra no fato de que o que vemos no vídeo é um "recorte", uma área de visão restringida. Não apenas no que concerne à largura e altura, mas também no que tange à profundidade. O espaço físico tridimensional ocupado pelo corpo do boneco e demais elementos que irão compor a cena sofrerão um "achatamento" ao habitarem a imagem no monitor, haja vista que essa imagem não possuirá uma profundidade "real" (pois, na imagem vista no monitor a profundidade é uma inferência dada pela relação dos elementos que compõem o quadro ${ }^{10}$ ). Essa conversão de dimensionalidades que surge no processo de produção audiovisual, que parte da tridimensionalidade para a bidimensionalidade, do ponto de vista da manipulação, oferece uma série de novidades ao ator-animador, que deverá aprender a "habitar" esse novo espaço e, para isso, necessitará desenvolver mais algumas habilidades psicofísicas. Deverá aprender a projetar subjetivamente a identidade do personagem representado no espaço de interação virtual, de forma similar ao uso de "avatares" nos jogos e, com isso, redimensionar sua experiência humana, utilizando o boneco que manipula como parte de uma interface operacional da realidade dada pelo vídeo. Com a utilização do vídeo, abre-se a possibilidade de transcender alguns limites humanos por meio da imaginação desse novo "corpo" visualizado na tela, pois além do manancial de potencialidades do boneco como matéria-plástica, teremos à disposição novas ferramentas ofertadas pelos recursos tecnológicos, aumentando a gama de variações de manipulação para produção de efeitos: Na imagem do vídeo, podemos aplicar cenários e elementos de cena inexistentes na realidade do ator e do boneco (como no caso do cromaqui) e podemos alterar cores e distorcer a imagem, entre outras coisas.

Mas prefiro, antes, centrar em questões de primeira instância para o uso de bonecos no vídeo, que envolvem o contato inicial do ator e do boneco com a linguagem audiovisual e a compreensão do uso do espaço dentro do enquadramento em correlação com o espaço do ator com seu boneco. Esse contato se trata de um processo de aprendizagem e desenvolvimento de uma nova capacidade interativa, pois demanda um modo diferente de trabalho de manipulação e de uso do corpo do ator.

Eu diria que a imagem do boneco no vídeo não é exatamente um "parceiro"11 do ator que a manipula por meio do boneco como interface; a imagem do boneco se apresenta para além do que podemos entender como "extensão"12 do corpo do ator, pois a imagem do boneco, de certa forma, é um duplo "autônomo" no espaço virtual em que opera. Ou seja, o ator, sob este ponto de vista, confere apenas "parte" dessa autonomia à imagem a partir de sua atuação, dos movimentos qualificados de seu corpo $^{13}$, de tal forma a provocar, no boneco, índices de ações que se desdobrarão na imagem visualizada/virtualizada. O corpo do ator, por meio do boneco, não realizará, necessariamente, a ação que será inferida pela leitura da imagem no monitor. A leitura, a "construção mental da ação realizada" partirá de índices evidenciados (não apenas pelo ator, mas também pelo editor - como veremos adiante), mas será concretizada

\footnotetext{
${ }^{10}$ Note-se que a terceira dimensão (profundidade), quando representada no quadro, converte-se numa relação entre a escala dos elementos de composição, envolvendo a percepção de suas alturas e larguras no espaço que ocupam.

11 Como cita Roland Shön, ao falar especificamente do "teatro de marionetes", apud Noguès (2017, p.18, In: Móin-Móin - Revista de Estudos sobre Teatro de Formas Animadas, Número 17). Embora ele não esteja se referindo ao boneco no vídeo, tomo a expressão de forma livre.

12 Noguès (idem)
} 
pela imaginação do observador/espectador. Uma vez registrado e finalizado o processo, eis que a imagem se dissocia completamente dos meios de produção e ganha autonomia, adquire sua própria realidade. Consoante Marcel Martin,

A imagem fílmica é portanto, antes de tudo, realista, ou melhor, dotada de todas as aparências (ou quase) da realidade. [...] A imagem fílmica suscita, portanto, no espectador um sentimento de realidade em certos casos suficientemente forte para provocar a crença na existência objetiva do que aparece na tela. (Martin, 2005, p.27-8)

A "existência objetiva" da imagem percebida do boneco, que podemos nomear como "percepção de uma realidade ficcionada", é forjada em um complexo sistema que parte, efetivamente, do conhecimento e uso que o ator faz de seu corpo, para, seguindo uma aguçada observação, evocar aspectos de uma realidade que possa ser reconhecida pelo espectador.

Marina Estela Graça (2006), ao tratar de aspectos do processo técnico do Cinema de Animação, converge para tese similar exposta por Steve Tillis (1992) no campo estético do Teatro de Animação. Ela assevera que "No processo de fabricação do filme animado, o autor esforça-se por recuperar para si mesmo, para seu próprio gesto, 0 controle não só de todos os procedimentos técnicos, mas, igualmente, a origem da ilusão fílmica, que acontecerá graças à participação do espectador" (GRAÇA, 2006, p. 95). Podemos inferir, então, que serão os procedimentos técnicos do "autor" (ou, no nosso caso, o "ator" - e eventualmente o editor) aliados à imaginação participativa do espectador que irão laborar na "construção de uma presença transitória" (GRAÇA, 2006, p. 96). Sobre a técnica de animação, é relevante a fala de Leslie Bishko: "Os animadores intuem o comportamento físico das formas com base em sua experiência cinestésica no mundo" (Bishko, apud Graça, 2006, p. 96. Grifo meu). Questão análoga, como dissemos, também é verificada no estudo de Tillis (1992), quando defende o boneco como um "fenômeno de percepção" do espectador. Diz o pesquisador que o ator irá intermediar esse reconhecimento de aspectos alusivos à vida, pelo público, imprimindo no objeto forma, movimento e, frequentemente, fala.

Essa assertiva é capital para a compreensão do processo psico-físico do ator na animação: A propriedade no conhecimento da psicologia e da mecânica das ações que serão sintetizadas nos movimentos do boneco se dará por meio das experiências vivenciadas pelo seu corpo. Como salienta Arnaud Rykner, "de certo modo, a primeira máquina de produzir imagens foi o corpo do mímico (capaz de tudo imitar por sua plasticidade)"14 (In: Chabrol e Karsenti, 2013, p. 42).

Se Rykner aponta o corpo do mímico como "uma máquina apta a tudo imitar por sua plasticidade", o que pensar então dessas figuras construídas especificamente para este fim, operadas pelo humano? Elas seguem a mesma lógica da expressão corporal como um sistema de linguagem híbrido, no qual fragmentos de informação contidos em suas "formas, movimentos e falas" serão elaborados numa sintaxe de

\footnotetext{
13 "Movimentos qualificados", aqui, são entendidos como movimentos selecionados e aperfeiçoados de forma consciente para produzirem significado de forma mais eficiente dentro de um contexto de ação.

14 "En un sens, la première machine à produire des images serait alors le corps du pantomime (capable de tout imiter par sa plasticité). Et si ce même corps s'apparente de ce fait à la plaque vierge ou au papier blanc de la photographie (capable de retenir toute image qui lui sera présentée), il porte tout autant en lui l'avenir de l'image mécanique qui s'incarnera en 1895 dans l'invention des Frères Lumière". (Tradução nossa)
} 
leitura. A relação do ator com o boneco manipulado, na produção desses fragmentos de informação, centra-se no paradoxo de "parecer" sem "ser". A realidade é construída por elipses. Da ação, destaca-se somente a essência dos movimentos básicos, pois de outra feita, se guardados em minúcias esses movimentos, talvez não se tornem críveis, dadas as limitações do boneco. Este já foi assunto de vários estudos, mas citamos aqui uma consideração feita por Andre-Charles Gervais:

O paradoxo do bonequeiro está na tensão que ele deve se impor de ser realista com um boneco que, pela sua conformação e sua parte tornada estética, transpõe imediatamente este realismo em signos e em símbolos; é também a necessidade na qual ele se encontra de tentar fazer "exato" para tornar o personagem vivo e a estilização que o boneco produz por seu esforço, que transforma naturalmente os gestos copiados em gestos sugestivos. (Gervais, 1947, p. 34) ${ }^{15}$

Dessa forma, Gervais afirma que o boneco possui seus gestos limitados e não consegue "reproduzir" as ações plenas do ser vivo, o que o obriga a "evocar" essas ações por meio de esquemas simplificados que as sugerem ao espectador. Por isso o autor diz que ao espectador cabe uma "participação ativa", pois será a imaginação dele que completará as elipses provocadas pelos movimentos que o boneco não é capaz de executar. Ao ator, cabe a seleção desses movimentos de síntese da ação, que servirão como índices ao espectador. Gervais conclui sua ideia ao afirmar que "A linguagem do boneco não é mais do que uma sucessão de esquemas, de indicações sumárias de esboços. Ele é necessariamente simples, direto e requer do espectador uma participação ativa" (Gervais, 1947, p. 35) ${ }^{16}$.

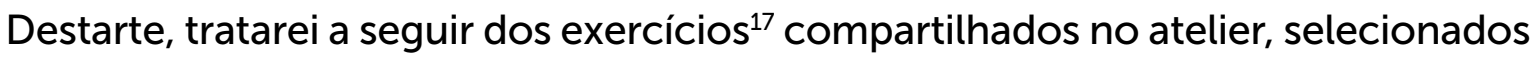
em função de seu curto tempo para realização e em função da abordagem de situações elementares para o preparo técnico do ator-animador. A compilação dos exercícios guiou-se pelos seguintes tópicos: 1) Uso do quadro e do extraquadro: o espaço do ator e do boneco; 2) Maleabilidade do corpo do ator e imobilidade do boneco; 3) Pontos focais: vetores de atenção dentro do quadro; 4) Eixo do boneco e desenho da caminhada no plano frontal e sagital.

Certamente, o breve estudo desses poucos tópicos é insuficiente para tratar de toda a complexidade da técnica da animação do boneco para o vídeo, mas acredito que propõe um bom começo de discussão sobre a metodologia.

Esclareço que o estudo e os exercícios que se seguem apontam para a prática específica do boneco de luva com boca articulada e varas para movimentação de seus braços ${ }^{18}$ (também conhecidos como bocones, na Espanha ${ }^{19}$ ). No entanto, mais

\footnotetext{
15 "Le paradoxe du marionnettiste est dans la tension qu'il doit s'imposer d'être réaliste avec une poupée qui, par sa conformation et son parti-pris esthétique, transpose immédiatement ce réalisme en signes et en symboles; c'est aussi la nécessite dans laquelle il se trouve d'essayer de faire "exact" pour rendre le personnage vivant et la stylisation que donne à son effort la poupée, qui transforme naturellement des gestes copiés en gestes suggestifs." (Tradução nossa)

16 "La langage de la marionnette n'est qu'une suite de schémas, d'indications sommaires d'esquisses. II est forcément simple, direct et il requiert du spectateur une participation active." (Tradução nossa)

17 Os exercícios apresentados são alguns dos quais tenho utilizado e desenvolvidas ao longo de vinte anos como formador de atores para o trabalho televisivo com bonecos. De forma empírica, tenho verificado nos estágios de formação, que a prática desses exercícios produz efeitos positivos a curto prazo, no que tange a um maior grau de consciência do ator-animador, tanto sobre seu corpo, quanto sobre o corpo do boneco e sua imagem.

${ }_{18}$ Este boneco costuma ter cerca de $60 \mathrm{~m} / 70 \mathrm{~cm}$ de altura, considerando apenas sua parte construída (da cintura para cima) e não sua parte imaginada pelo público (da cintura para baixo). O que corresponderia a uma "altura ficcionada" - imaginada pelo público - entre 1,20m e 1, 40m.

${ }^{19}$ Ver Amorós e Parício (2000) e Parício (2006).
} 
do que as especificidades dessa técnica, o processo pedagógico de manipulação e observação simultânea por meio de um monitor almeja refletir sobre os caminhos que a consciência do ator pode percorrer para se "identificar" não apenas no boneco como sendo seu duplo, mas também no desdobramento do boneco nessa projeção em ambiente virtual que é presentificada na imagem produzida no vídeo ${ }^{20}$. A escolha deste tipo de boneco ocorreu pela razão de que, nesta técnica operacional, o braço do ator simula a coluna vertebral do boneco e as distintas articulações de seu braço repercutem nas articulações do corpo do boneco de forma direta. Assim, é possível ao ator "sentir" o corpo do boneco em seu próprio corpo, em contraponto à percepção da imagem do boneco no vídeo, que não pode ser "sentida" diretamente (até mesmo porque existe uma pequena "defasagem" entre o tempo em que o movimento do boneco é produzido e o tempo em que este movimento repercute na imagem do monitor). Além disso, essa técnica propicia uma enorme gama de movimentos a serem utilizados de forma mimética, quer dizer, a quantidade de articulações que o boneco possui, e sua precisão em resposta ao comando do ator, possibilita executar uma representação mais ou menos fidedigna do movimento humano, guardada as singularidades que o boneco possui no que tange à síntese e à sugestão da ação ${ }^{21}$. Esta representação do movimento constitui importante ferramental de observação e análise do "humano" e do "personagem" para o ator, visto que a "síntese" exige grande esforço cognitivo para selecionar características essenciais que possam defini-los e lhes imbuir de expressão.

\section{Uso do quadro e do extraquadro: o espaço do ator e do boneco}

A primeira coisa que precisamos ter em conta é que, embora essas duas linguagens, animação e audiovisual, apresentem suas particularidades, existem muitos pontos de intersecção ${ }^{22}$. Esse reconhecimento auxiliará bastante em muitas resoluções técnicas.

O audiovisual (cinema e televisão, posteriormente), ao longo de sua história, consagrou alguns formatos de projeção de imagem, que inicialmente estavam ligados ao suporte o qual era utilizado para o registro da imagem. E eis que hoje ainda preservamos muito do vocabulário que foi utilizado no princípio do cinema, como, por exemplo, a palavra quadro.

A noção de quadro se refere ao espaço bidimensional que será visto pelo telespectador. Possui altura e largura, sendo que a profundidade é apenas uma Inferência ocasionada pela relação da composição dos elementos na produção de perspectiva. $O$ campo de profundidade, assim, é percebido na sintaxe, na relação entre os elementos que compõem o quadro em conjunto com o que estipulamos como sendo nossa linha do horizonte/ponto de fuga.

\footnotetext{
${ }^{20}$ Portanto, para os exercícios praticados, além do ator e do boneco, fez-se necessária a presença de uma câmera posicionando um enquadramento fixo e um grande monitor, para que todo o grupo pudesse acompanhar simultaneamente o processo do ator-animador e o resultado obtido no monitor (quadro).

${ }^{21}$ É importante lembrar que o boneco é um objeto incompleto, e seu movimento é um esquema simplificado que propicia a inferência do movimento real. É por sugestão que o público consegue "ler", identificar uma ação.

${ }^{22}$ Uma ótima referência para pesquisa nesta área é o pré-cinema, o percurso desenvolvido pelas diferentes invenções que tornaram possível o cinema (lanterna mágica, projeção de imagens, fotografia, etc.). Outra referência é o trabalho de George Méliès (1861-1938), um dos precursores do ilusionismo no cinema (A vida de Méliès foi inspiração para o filme de Martin Scorcese A invenção de Hugo Cabret, 2011)
} 


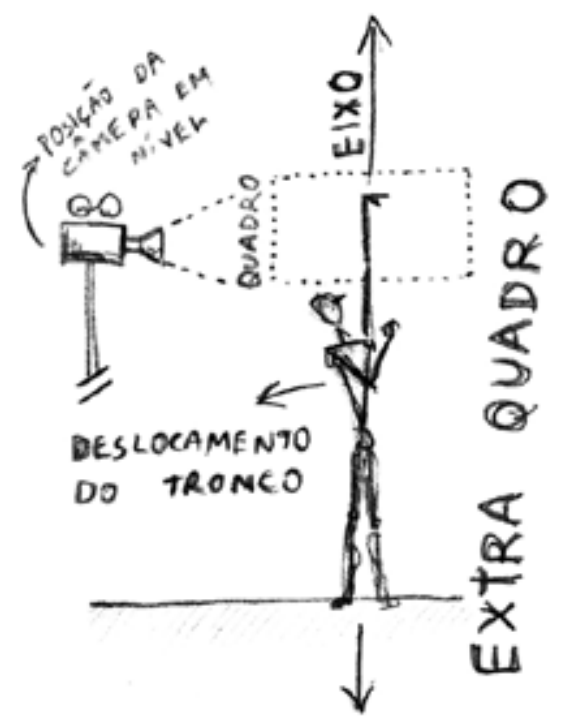

Figura 1 - Câmera em nível, quadro e extraquadro

O quadro acima apresenta o recorte de um todo e, na edição das imagens, o modo como a justaposição de quadros é articulada pode assumir importante papel na dramaturgia ${ }^{23}$.

Devemos considerar também que, para o ator-animador que trabalha com o vídeo, tão importante quanto uma boa desenvoltura do boneco no quadro é o entendimento do extraquadro: este é o espaço de todo o processo de construção do que veremos no quadro, que não é visto e não deve ser imaginado pelo telespectador (presume-se). O extraquadro funcionará como uma empanada ${ }^{24}$ "invisível", visto que o recorte da área visível será dado pela câmera (por meio do plano). Quer dizer, a câmera fará a seleção da área que que deverá ser de interesse para o telespectador, e será fora desta área que o ator-animador irá se locomover. Ao contrário do quadro, o extraquadro é um espaço tridimensional que pertence à realidade do ator: ele precisará se mover nesse espaço para produzir a imagem necessária dentro do quadro (que representará o espaço ficcional). Portanto, útil será também para o cenógrafo compreender que, em seus cálculos e medidas, ele deverá considerar a escala do corpo humano que atuará no extraquadro. Pode parecer óbvio, mas não é: às vezes a preocupação é demasiada com a composição do quadro, com a iluminação e, num descuido, o ator acaba ficando sem espaço suficiente para mover o boneco. É importante lembrar que este tipo de boneco é um modelo em escala reduzida do corpo humano, mas não está desvinculado do corpo do ator. Existem alguns limites para sua movimentação, principalmente no que se trata de locomoção num espaço onde haja muitos elementos cenográficos, os quais podem dificultar a performance do ator. Quer dizer: obstáculos que bloqueiem o deslocamento do ator, que dificultem a visibilidade do monitor (que serve como um guia para a mobilidade e foco do boneco) ou que prejudiquem a movimentação dos braços do ator, afetarão a manipulação.

\footnotetext{
${ }^{23}$ A construção do "sentido" na cena fílmica é, em grande parte, arquitetada na montagem, que envolve a seleção, a justaposição e a determinação da duração dos fragmentos compostos pelos diferentes planos. Essa teoria foi verificada no experimento conhecido como "efeito Kuleshov", desenvolvido no cinema experimental soviético dos anos 1920. Serguei Eisenstein (1898-1948), também defendeu o poder da montagem para construção de ideias, criando a técnica conhecida como "montagem intelectual" ou "dialética".

${ }^{24}$ Tapadeira, palco de teatro de bonecos tradicional que oculta 0 ator-animador.
} 
Vale notar que, a título de efeito, o quadro pode manifestar um espaço multi- gravitacional para o boneco, quer dizer, o boneco pode subverter a lei da gravidade e realizar entradas e saídas por qualquer um dos quatro lados. Mas isto só ocorrerá se houver a possibilidade de o ator-animador operar com liberdade no extraquadro. Isto quer dizer que o boneco poderá surgir de cima para baixo, de baixo para cima e lateralmente, sem restrições. No entanto, para isso, é necessário criar zonas de trânsito acessíveis para o ator-animador, para que ele possa se deslocar fácil e confortavelmente sem ser "visto" pela câmera, ou, compor esse efeito na montagem. É desta facilidade e conforto no deslocamento do ator-animador que dependerá a boa desenvoltura de seus movimentos na manipulação, pois se o seu corpo estiver em desconforto ele terá maiores dificuldades em operar o boneco. Normalmente, é no extraquadro que ocorrem resoluções técnicas que não são vistas pelo público, ao qual é dado somente a imagem como produto já resolvido na tela.

Nas condições com as quais o ator-animador opera seu boneco, sua posição, elementos de cena e recorte do quadro, é desejável que ele possa ter acesso à imagem que está sendo captada em tempo real: isso facilita toda sua movimentação e inclusive, amplia sua expressão, uma vez que ele tem acesso à imagem que está sendo capturada num determinado plano e ângulo, podendo brincar confortavelmente com o "espaço recortado" do quadro.

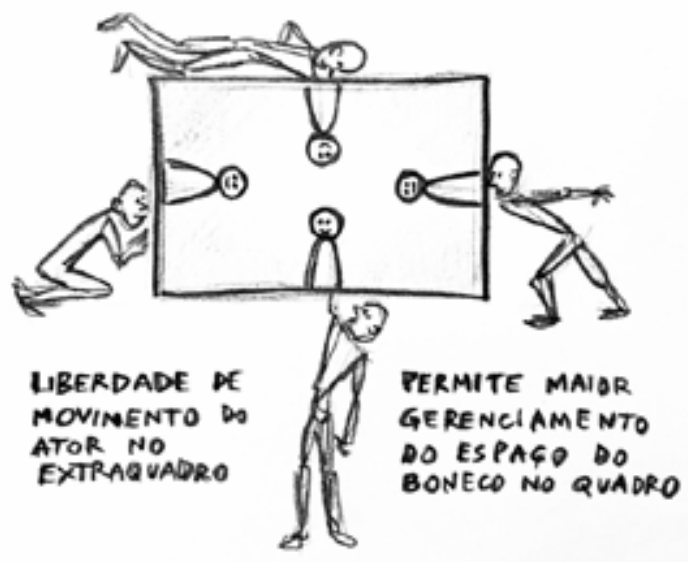

Figura 2 - Ocupação do quadro

No audiovisual, o uso de monitor para os atores-animadores é de uso imprescindivel. O monitor são os "olhos" do ator-animador no vídeo. Sem ele, o trabalho fica "às cegas". E é com o uso deste monitor que percebemos uma maior consciência do movimento realizado na tela a partir dessa projeção subjetiva na imagem visualizada, beneficiando a qualidade da manipulação, principalmente em aspectos de precisão e síntese. Dessa forma, a auto regulação e correção do movimento é muito mais eficaz, uma vez que não depende apenas do "sentir" no corpo do ator, mas é também facilitada pela observação do resultado final do movimento em si, resultando no melhor aproveitamento possível da ação em cada plano.

\section{Maleabilidade do corpo do ator e imobilidade do boneco}

O corpo do ator, convertido no duplo do boneco desdobrado à pixalização por meio da captura de sua imagem, ocupa outro espaço: um espaço passível de 
ser manipulável e visível na tela. No entanto, habitar esses espaços simultâneos irá requerer um preparo especial do corpo do ator.

O recurso da observação do monitor pelo ator-animador em tempo real de manipulação, para guiar a movimentação, direcionar o foco do olhar do boneco e auxiliar no posicionamento dentro do enquadramento, é muito eficiente. Mas para isso, é preciso que o ator-animador se habitue ao seu uso, o que demanda um certo tempo de prática para que o corpo aprenda a responder automaticamente aos estímulos visuais percebidos no monitor. O vídeo realiza uma "quádrupla" existência simultânea do ator-animador: ele é o artista-ator, o personagem-boneco, a imagem virtualizada do personagem-boneco e o telespectador. Isso acrescenta dificuldades ao seu trabalho, pois ele necessitará aprender a gerenciar e mediar todas essas percepções múltiplas, tendo em conta que a imagem vista no monitor é o simulacro do boneco.

Por meio do monitor, temos um recurso que auxilia na consciência pelo movimento: junto com a percepção corporal pelo ator, temos o feedback visual em tempo real, sob o ponto de vista de que ele também é receptor. Assim, o ator pode estar "dentro" e "fora" da ação, ou seja, pode se distanciar e assumir o ponto de vista do telespectador instantaneamente (numa visão externa), sem deixar de se ausentar na manipulação. Esse procedimento lhe facilita para corrigir automaticamente a ação ou a posição do boneco. No boneco que atua no teatro, em comparação, essa situação é mais difícil de ocorrer, pois o ator-animador está inserido na cena e sua visão é interna e parcial. Quer dizer, ele não possui o mesmo ângulo de visão do público. Além disso, no teatro, o público seleciona "em quê" irá focar sua atenção: num personagem, num detalhe do cenário, na iluminação, etc., ao passo em que, no vídeo, já existe uma pré-seleção dada pela edição. Essa pré-seleção apresenta um fracionamento do material registrado pelo vídeo. Por isso, a atuação do ator-animador frente à captura de imagem deve compreender que as ações executadas pelo boneco serão decompostas e articuladas em diferentes planos, segmentos dissociados, que ainda serão manipulados posteriormente na edição. E será na edição que serão concretizadas as conexões para induzir ao sentido.

Muito do meu interesse no desenvolvimento de técnicas para o aprendizado, ou metodologia para o ensino, surgiu no período em que fui contratado para criar os personagens-bonecos e formar atores-animadores para o programa Mundo da Leitura $^{25}$. A atriz que iria manipular a protagonista tinha algumas dificuldades na realização de movimentos com as mãos, o que afetava na manipulação. Neste momento, necessitei elaborar um programa de trabalho que estimulasse a sua sensibilidade e, principalmente, que a possibilitasse descobrir como fazer bom uso de suas limitações. Uma ideia que colaborou muito foi a de que o boneco deveria se mover menos. Quanto menos ela se movesse, mais precisão teria. É claro que, no caso do vídeo, a possibilidade de repetir a cena e a edição também colaboram muito, pois se pode recortar e embaralhar as imagens até chegar no produto final.

No caso dessa atriz, vejo que era mais importante fazer uso consciente de suas capacidades do que tentar desenvolver habilidades complexas demais ${ }^{26}$. Iniciamos

${ }^{25}$ A formação dos atores ocorreu entre os anos de 2005 e 2009. O programa foi uma iniciativa do Centro de Referência em Literatura e Multimeios da Universidade de Passo Fundo, RS em parceria com a TV Futura e tinha como meta estimular a leitura de forma divertida e utilizando multimeios. Foi produzido até 0 ano de 2017. 
com alguns exercícios simples, com movimentos mínimos e, pouco a pouco, fomos reconhecendo essas capacidades. Este trabalho esclareceu-me sobre a importância de conter os movimentos do boneco no vídeo. Esta hipótese tenho testado em todos os cursos de formação que ministro e toda metodologia aplicada nos cursos pretende reduzir o esforço do ator ao mínimo, buscando sempre a máxima expressão com a imobilidade para, a partir desse momento, iniciar a pesquisa de simulação de respirações, pequenos movimentos e reconhecimento das articulações disponíveis no boneco.

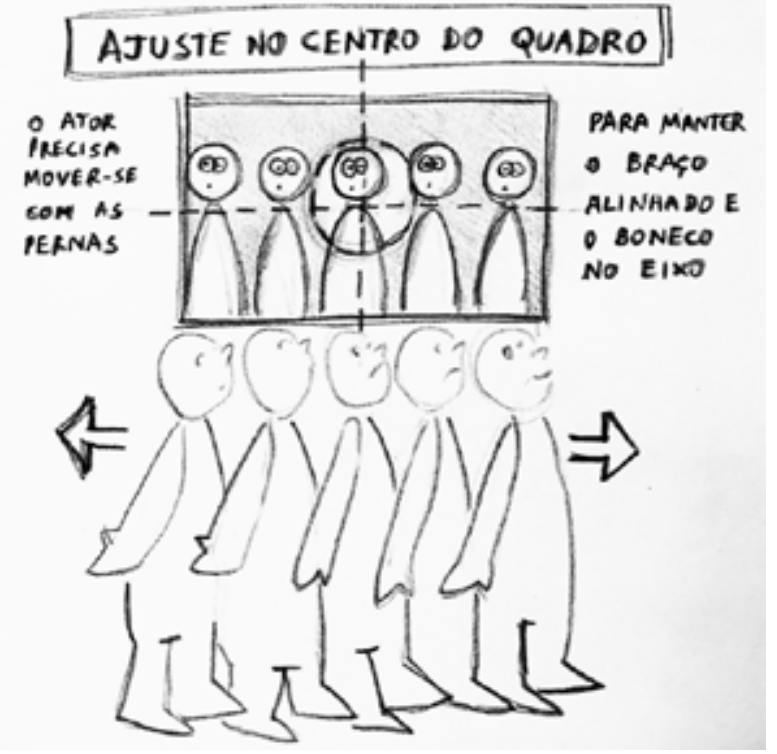

Figura 3 - Manter o boneco no eixo no centro do quadro

Assim, numa instância inicial, opto por configurar procedimentos sistêmicos que colaboram para observar e analisar criticamente a possibilidade de comunicar com a imobilidade e com o mínimo de movimentação possível. Com isso, o aprendizado do corpo do ator é estimulado a ser cuidadoso e sutil, dedicando-se à economia e à síntese.

No aspecto da captação da imagem, uma das primeiras coisas e mais difíceis a realizar é manter-se no quadro. Eu costumo brincar dizendo: "pare se puder". A imobilidade é, de fato, apenas um conceito, uma busca contínua que demanda um esforço, visto que tudo se move o tempo todo. Se não há movimento visível, há um movimento interno imperceptível; se algo parece imóvel, é apenas uma questão de perspectiva temporal ou produto da imaginação do observador. Mesmo uma montanha, se pudéssemos observar por um tempo indefinido, veríamos que, com os séculos e pela interação com o ambiente, ela pareceria dar a impressão de que "se move".

Nosso corpo jamais restará "imóvel". A imobilidade é uma grandeza absoluta e inapreensível, assim como a neutralidade, o infinito e a morte. Nosso corpo não para jamais de se mover. O objetivo do exercício de imobilidade que é proposto consiste em tornar cada vez mais imperceptível o movimento, tomando consciência de tudo que impulsiona o corpo a se mover e, pouco a pouco, gerenciar esses impulsos. Neste exercício, o ator deve se esforçar por manter o boneco atento ao eixo imaginário que desenha sua coluna vertebral, que deverá estar em posição perpendicular à base do

\footnotetext{
${ }^{26}$ Anca Ciobotaru, em sua conferência durante o encontro Pro-Vocation, em Targoviste, 2017, nos disse: "Nossos resultados não representam nosso potencial, mas nosso nível de consciência". Por isso, uma avaliação eficiente reflete sobre o desenvolvimento de um processo individual, dentro de determinadas expectativas tidas como "naturais" e integradas a um contexto.
} 
quadro. Para obter essa posição, é preciso deixar o braço do ator esticado para cima e na posição vertical, executando um pequeno deslocamento lateral do tronco do ator, para que o eixo do boneco se alinhe com o eixo do corpo do ator (conforme podemos observar na figura 1). Sem esse deslocamento do tronco e alinhamento de eixos, fica mais difícil a execução de giros e deslocamentos no quadro sem perder o eixo do boneco. Um delicioso desafio é manter-se imóvel com o boneco no centro exato do quadro, fazendo com que seu foco se direcione para os olhos do telespectador. A princípio o corpo do ator fica tenso (e podemos perceber isso também pelo seu duplo: o boneco torna-se rígido). Mas, aos poucos, o ator descobre que não é uma questão de força ou tensão, apenas consciência e reorganização da arquitetura de seu corpo, que deverá funcionar de "outro modo"27 para amplificar a presença do corpo ficcional visto na imagem do boneco. Mais relaxado, podemos perceber a presença de "micro-movimentos" no corpo do boneco, os quais, coordenados, poderão causar efeitos surpreendentes, conferindo enorme vivacidade ao personagem.

Manter-se em quadro está conectado com o reconhecimento de nossa autoimagem projetada não somente no boneco que manipulamos, mas também em seu duplo virtual: é o corpo do ator "triplicado". Nesse processo, a imagem que é vista no monitor deverá ser também sentida pelo corpo do ator. A identificação com a imagem do boneco fará com que este exista/reaja no espaço do monitor. A localização espacial no quadro é virtualizada, e o que aparece nele nem sempre corresponde à realidade do ator. Os limites do espaço ocorrerão na mente do ator-animador, adaptada ao recorte do enquadramento, a qual recriará um modelo mental para esse espaço que vê na tela e operará com o boneco dentro desses limites: uma fôrma invisível determinará a amplitude dos movimentos do boneco ${ }^{28}$.

Nesta problemática, com alguns exercícios simples podemos abordar questões práticas no nível pré-expressivo do boneco: começando pelo eixo, foco e fixação de pontos no espaço (Como, por exemplo, na figura 4, na qual o cotovelo do ator se mantém num ponto fixo para que o boneco possa se curvar sem perder sua altura de referência do quadril). Isto possibilita estabelecer limites imaginários para a área de atuação.

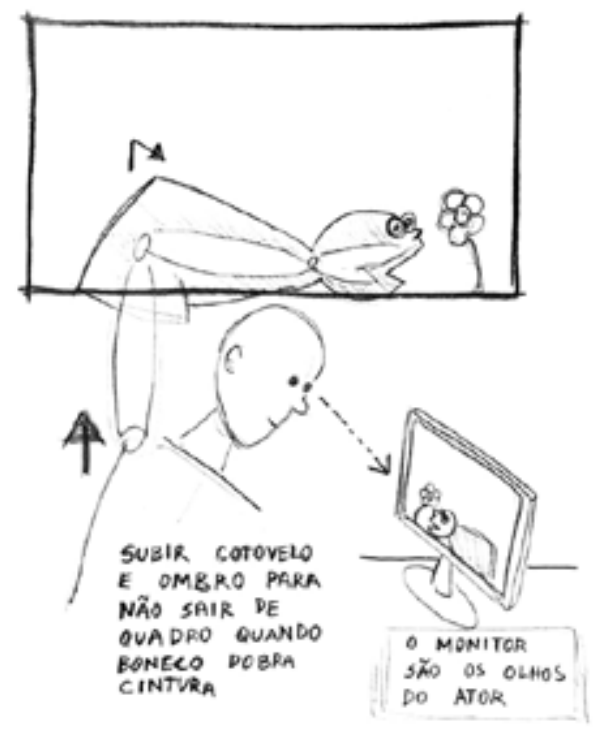

Figura 4 - Uso do monitor como controle da imagem

\footnotetext{
${ }^{27}$ Podemos cruzar este estado do corpo do ator-animador com o conceito de "corpo extra cotidiano", de Eugênio Barba (1995).

${ }^{28} \mathrm{O}$ processo de construção de um espaço virtual de atuação, hoje, é corriqueiramente utilizado pelo cinema, por meio do motion capture.
} 
Dentre alguns exercícios que envolvem ações simples com o corpo do boneco em estado de imobilidade mínima, podemos destacar: 1) Respirar, inspirar e expirar; 2) Diferenciar "perceber algo" de "assustar-se"; 3) Diferenciar "olhar" de "enxergar".

\section{Pontos focais: vetores de atenção dentro do quadro}

Fazer com que o boneco pareça estar olhando para aquilo que the é de interesse é essencial para causar a ilusão de que ele é autônomo. O uso do monitor auxilia a perceber quando o olhar do boneco converge para determinado "ponto focal". Para auxiliar no desenvolvimento dessa competência, um recurso que pode ser utilizado é aplicar, no monitor, alguns adesivos com números que indiquem para onde o olhar deve mirar (Como vemos na figura 5).

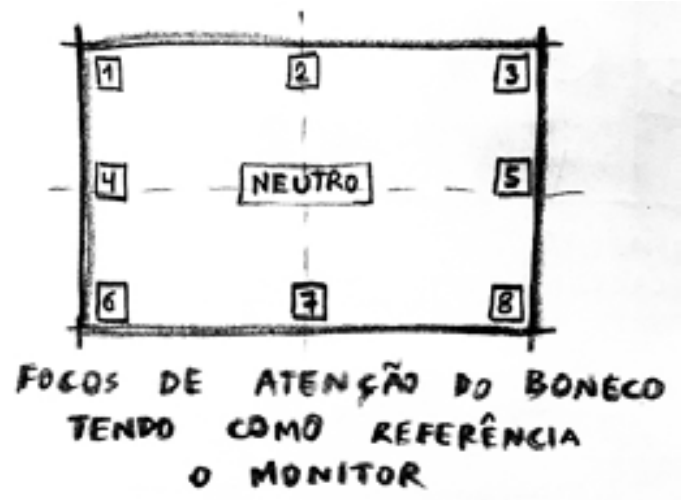

Figura 5 - Pontos focais para exercícios com bonecos

Alguns exercícios que envolvem ações simples com o corpo do boneco em estado de imobilidade mínima têm demonstrado bons resultados nos cursos: 1) Observar pontos do enquadramento (de 0 a 8 , retornando à posição neutra). $O$ ator pode ser estimulado com indicações do tipo "olhe...uma formiga no ponto 6 , uma nuvem no ponto 3, seus pés no ponto 7, casa ao lado no ponto 4...", e assim por diante; 2) Transferência de foco de um ponto outro com inclusão de dinâmicas de velocidade. Neste exercício, novamente, os estímulos podem colaborar para a visualização do ator e para a execução do movimento do boneco. $O$ boneco pode ser solicitado para observar uma flor que nasce - movimento vertical da cabeça, de baixo para cima/ lento; observar um carro que passa - movimento horizontal da cabeça, de um lado para outro/rápido; observar um avião que decola - movimento diagonal da cabeça, de baixo para cima/lento; observar uma fruta que cai - movimento vertical da cabeça, de cima para baixo, rápido; etc.

\section{Eixo do boneco e desenho da caminhada no plano frontal e sagital}

Depois que o ator-animador desloca seu eixo para lateral, cedendo espaço para que o boneco assuma o eixo central do corpo do ator, a manutenção do eixo do boneco é dada pelo movimento do ombro ou do cotovelo do manipulador, mantendo os pés fixos no chão. 


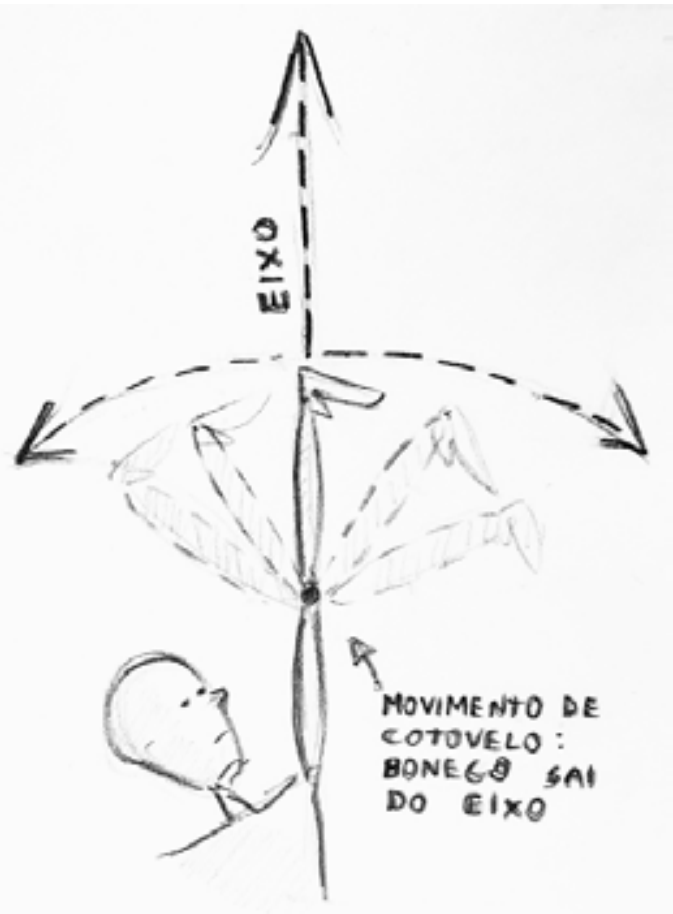

Figura 6 - Movimento do cotovelo

Tenho percebido que os alunos não conectam suas pernas com as pernas dos bonecos. Fragmentam seu corpo e não deixam a energia circular por ele. As vezes é necessário "dissociar" alguns movimentos, sim, mas as vezes é preciso associar de outra forma: o corpo é uma unidade biológica. Melhor do que pensar em "dissociar", talvez fosse melhor a imagem de "polarizar" o fluxo de energia do corpo. Tal como criar um polo magnético para o qual o movimento irá convergir. Esta ideia nos faz pensar no corpo com um campo magnético ao seu redor, com um polo que atrairá o olhar. Ou seja, gerenciaremos a energia do corpo para que todo ele possa se adaptar e concentrar seu maior grau de expressividade, no caso do boneco de luva, no braço e na mão do ator.

Pensamos então na ideia de polarização ou magnetização como uma metáfora para substituir a ideia de "dissociação", a qual pode induzir a uma falsa sensação de que o corpo pode ser fragmentado e operar sobre partes isoladas.

Por mais que controlemos uma parte específica do corpo, produzindo movimento, todos os outros músculos estarão implicados, pois haverá informações que indicarão quais músculos deverão estar sem tensão e quais deverão estar tonificados.

O uso do termo "dissociação" talvez não colabore tanto, pois não se está separando o corpo, dissociando. O que estaremos nos esforçando é por reorganizá-lo, intensificando e distribuindo diferentes qualidades de energia (estática, contida, fluída, explosiva) por diferentes endereços no mapa de nosso corpo. Devemos imaginar que vamos passear por esse mapa e visitar algumas regiões, mas o espaço global continuará ali.

Para a caminhada do boneco, uma vez que cotovelo e ombro estejam no eixo, serão os pés do manipulador que irão caminhar para deslocar o boneco de um lado a outro e posicioná-lo no centro do quadro. Deslocar o boneco (como no caso de uma caminhada) simulando os passos do boneco por meio dos passos do ator-animador pode ajudar a manter não apenas o eixo, mas também a altura do boneco. 
Sobre a altura, e também sobre a amplitude dos movimentos do boneco, incluindo os passos ao caminhar, é conveniente resguardar a escala do boneco: se a altura do boneco corresponde a $3 / 4$ da altura humana, a amplitude de seus movimentos deverá também corresponder a esta proporção, como no caso dos passos. Isto quer dizer que, se nossos passos irão produzir a impressão de caminhada do boneco, esses passos deverão ter sua amplitude reduzida em $3 / 4$.

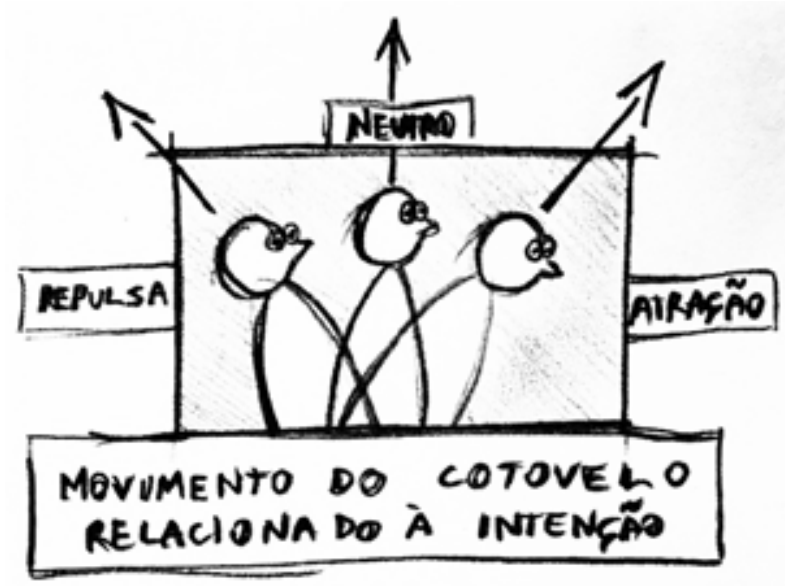

Figura 7 - Repercussão do movimento do cotovelo

Sobre a impressão de caminhada, percebemos dois importantes movimentos na caminhada humana que se sobressaem: enquanto numa vista lateral a altura do boneco produz uma oscilação ao longo de sua caminhada (figura 9), numa vista frontal do movimento, perceberemos um balanço lateral (figura 10). Alguns exercícios básicos para prática de caminhadas com os bonecos: 1) Cruzar a cena caminhando em linha reta; 2) Cruzar a cena percebendo algo; 3) Dois desconhecidos se cruzam; 4) Dois conhecidos se encontram no centro do quadro e se cumprimentam.

É importante trabalhar com a economia dos movimentos dos bonecos em frente à câmera. Principalmente nos planos fechados, pois movimentos amplos demais poderão fazer o boneco perder o foco ou mesmo jogá-lo para fora do quadro. Um dos benefícios que o trabalho em vídeo promove é o aprendizado da sutileza dos movimentos e da economia de gestos: concentrar em produzir as ações somente dentro do quadro; fora do quadro, é sempre aconselhável relaxar o corpo do ator, pois as gravações tendem a ser longas e exaustivas ${ }^{29}$.

\footnotetext{
${ }^{29}$ Não podemos esquecer que o modo de produção, no audiovisual, é fragmentado. A captação de imagens se dá de modo descontínuo no que se refere ao espaço e ao tempo da narrativa, pois obedece a regras de organização e economia do tempo para sua realização. Desta forma, também, a construção do personagem ocorre de forma fragmentada: entre os inúmeros cortes e troca de planos, o ator-animador tenta reestabelecer o liame entre suas ações. Além disso, no audiovisual, essa progressão do personagem acaba, muitas vezes, na mão do diretor e do editor, os quais irão construindo os sentidos da interpretação a partir da seleção de planos e imagens que serão "coladas". Assim, o produto final será constituído a partir da organização desse mosaico de fragmentos de imagens.
} 


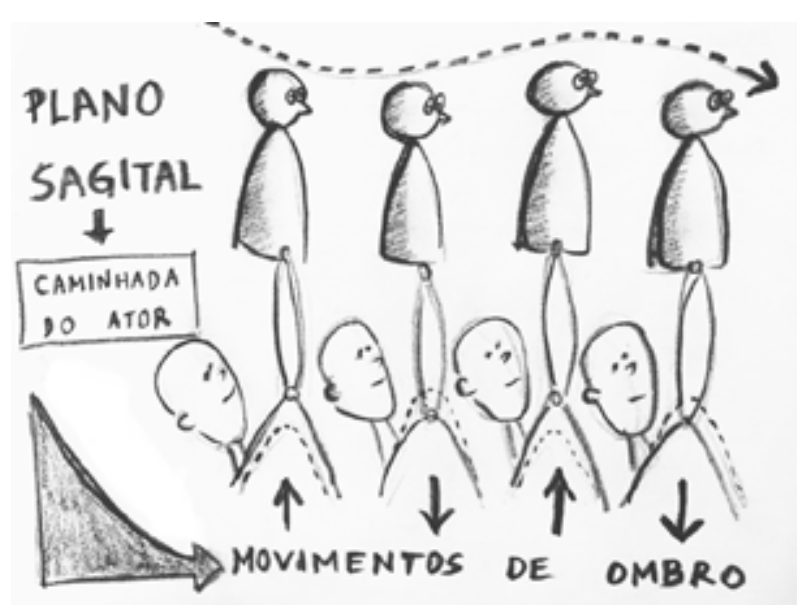

Figura 8 - Deslocamento do boneco, vista lateral

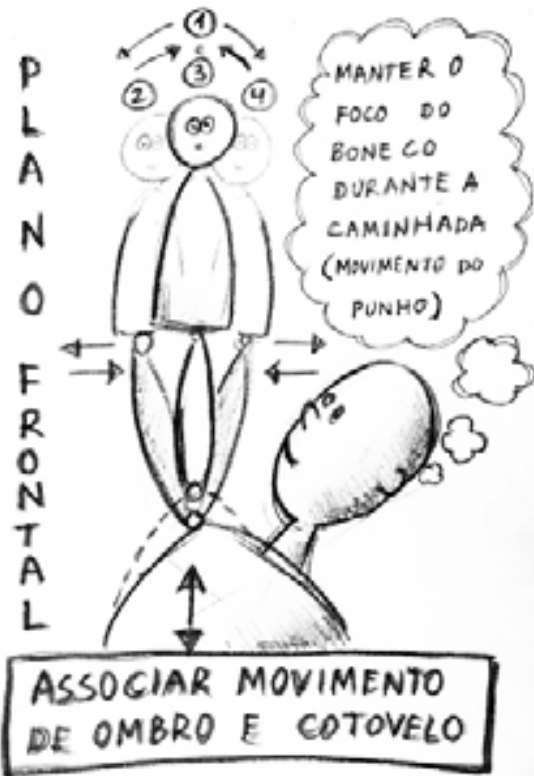

Figura 9 - Deslocamento do boneco, vista frontal

\section{À guisa de uma conclusão}

É claro que os atalhos de aprendizado existem e estão muito mais relacionados com a paixão que é dedicada ao aprendizado do que com a burla de etapas do processo cognitivo. Uma boa metodologia também colabora para que aspectos importantes da linguagem, principalmente no uso de técnicas e ferramental, não passem desapercebidos. Dessa forma, a capacitação depende, algumas vezes, na concepção que o artista faz de sua própria arte e da necessidade de ampliação do potencial de sua expressão para a realização de uma ideia. Se uma boa prática é grande formadora, devemos estar cientes de que uma instrumentalização bem estruturada também colabora muito para o desenvolvimento do artista. Técnicas e métodos de formação podem oferecer variadas abordagens para desenvolver o autoconhecimento e podem propiciar estímulos positivos se forem compartilhadas com generosidade.

Os conceitos aqui apresentados não significam que todos os bonecos devam sempre fazer ou agir conforme os preceitos expostos. Devemos discernir um exercício técnico, com vistas ao desenvolvimento pré-expressivo, do trabalho de criação artística. Embora os dois processos estejam interligados, constituem etapas diferentes. Se, na etapa pré-expressiva, a repetição e o estudo criterioso das minúcias desenvolverão o espírito crítico e domínio do movimento, no processo criativo o boneco pode se apresentar como um meio de transgressão da realidade em diversos níveis: pois ele pode realizar coisas impossíveis para nós, humanos, e invocar o pensamento mágico. Por isso optei por arguir sobre a qualificação da manipulação para fins de reprodução mimética do movimento humano com esta técnica específica de bonecos, apresentando algumas práticas aplicadas aos meios audiovisuais e lançando sobre eles um olhar pedagógico. Observar-se a si e ao mundo é um primeiro aprendizado, uma via de acesso que traz a inquietação com os porquês, instiga a representação e mobiliza o prazer pela investigação. 
Do ponto de vista pedagógico, em última análise, recursos com câmeras de vídeo e monitores, e mesmo outros dispositivos, mais corriqueiros, tais como telefones portáteis, micro câmeras de segurança e tablets também podem servir como valioso ferramental para abordar a linguagem da animação, seja pela viabilidade de captura e manipulação da imagem, seja pela praticidade e eficácia para o ator obter um feedback ou até mesmo pela possibilidade de compartilhar as imagens nas redes sociais. O importante é que a técnica, tomada como um exercício constante, não seja enfadonha e que o praticante se sinta estimulado em continuar seu aperfeiçoamento.

\section{Referências}

AMORÓS, Pilar; PARÍCIO, Paco. Títeres y titiriteros el lenguaje de los títeres. Zaragoza: Mira, 2000.

BARBA, Eugênio; SAVARESE, Nicola. A arte secreta do ator. São Paulo: Hucitec, 1995. CONVERSO, Carlos. Entrenamiento del titiritero. Iztapalaga: Escenología, A.C., 2000. GERVAIS, Andre-Charles. Marionnettes et marionnettistes de France. Paris: Bordas,1947.

GRAÇA, Marina Estela. Entre o olhar e o gesto: elementos para uma poética da imagem animada. São Paulo: SENAC, 2006.

HÉBERT, Chantal; RERELLI-CONTOS, Irène. L'écran de la pensée. In: PICON-VALLIN, Béatrice. Les écrans sur la scène. Lausanne, Suisse: Editions L'Age d'Homme, 1998.

MARTIN, Marcel. A linguagem cinematográfica. Portugal: Dinalivro, 2005.

NOGUĖS, Joëlle. Transfiguração dos corpos. Os corpos pensantes. In: BELTRAME, Valmor Nini; MORETTI, Gilmar Antônio (ed.). Móin-Móin - Revista de Estudos sobre Teatro de Formas Animadas. Número 17. Jaraguá do Sul, 2017.

PARÍCIO, Paco. Títeres y demás parientes. Jaca: Pirineum Editorial, 2006.

RYKNER, Arnaud. Pantomime, pré-cinéma et cinéma: transferts, pulsions, modèles. In: CHABROL, Marguerite; KARSENTI, Tiphaine (dir.). Théâtre et cinéma, le croisement des imaginaires. Rennes: Presses Universitaires, 2013.

SANTAELLA, Lúcia. Entrevista para o programa Canal Sempre Um Papo, publicada em 26 de março de 2009. Disponível em https://www.youtube.com/watch?v=XhRgfLuZXNY. Acesso em 01/04/2018.

SANTANA, René Férnandez. Método de manipulación y trabajo del actor en el teatro de títeres. La Havana: Editorial Pueblo y Educación, 1989.

TILLIS, Steve. Toward an Aesthetics of the Puppet: Puppetry as a Theatrical Art. Connecticut: Greenwood Press,1992.

Recebido em: 24/05/2018

Aprovado em: 24/05/2018 